\title{
QUAIS COMPORTAMENTOS TÁTICOS DE JOGADORES DE FUTEBOL DA CATEGORIA SUB-I 4 PODEM MELHORAR APÓS 20 SESSÕES DE TREINO?
}

\author{
MS. CARLOS RAPHAEL BRAGA CORRÊA DE SOUZA \\ Programa de Pós-graduação em Ciências do Desporto, \\ Faculdade de Desporto, Universidade do Porto \\ (Rio de Janeiro - Rio de Janeiro - Brasil) \\ E-mail: souza I I@gmail.com
}

\author{
MS. EZEQUIEL STECKLING MÜLLER \\ Instituto Federal de Educação, Ciência e Tecnologia Catarinense - \\ Campus Luzerna (Luzerna - Santa Catarina - Brasil) \\ E-mail: zekmuller@gmail.com \\ DR. ISRAEL TEOLDO COSTA \\ Departamento de Esportes, Universidade Federal de Viçosa \\ (Viçosa - MG - Brasil) \\ E-mail: israelteoldo@gmail.com \\ DR. AMÂNDIO BRAGA SANTOS GRAÇA \\ Departamento de Pedagogia, Faculdade de Desporto, \\ Universidade do Porto (Porto - Porto - Portugal) \\ E-mail: agraca@fade.up.pt
}

\begin{abstract}
RESUMO
O objetivo deste trabalho foi avaliar quais os comportamentos táticos podem ser alterados após 20 sessões de treino. A amostra foi composta por 18 jogadores da categoria sub- 14 . 0 instrumento utilizado para a avaliação dos comportamentos táticos foi o FUT-SAT e as sessões de treino foram baseadas no Teaching Games for Understanding. Verificaram-se diferenças significativas em quatro variáveis: no Princípio Tático "unidade defensiva", no total de ações táticas realizadas, no Índice de Performance Tática de Jogo e no Percentual de Erros do Princípio Tático "espaço". Concluiu-se que os treinos foram eficazes, especialmente, no que diz repeito ao aumento do Índice de Performance Tática do Jogo.
\end{abstract}

PALAVRAS-CHAVE: Futebol; tática; treino; Teaching Games for Understanding. 
O futebol pertence ao grupo dos jogos esportivos coletivos de invasão, sendo caracterizado como um jogo de cooperação/oposição em que duas equipes realizam ações simultâneas sobre a bola em contexto aberto (REVERDITO; SCAGLIA, 2007). Estas características conferem imprevisibilidade, o que implica em constante necessidade de adaptação das ações táticas dos jogadores ao contexto apresentado no momento (CASTELO, I994; GARGANTA; PINTO, I 994; GRAÇA, 1994). O conceito de tática abrange todas as decisões tomadas pelos jogadores em uma partida, com ou sem a bola, na relação individual ou coletiva, de cooperação ou oposição (TEODORESCU, 1984). Uma vez que os fatores táticos são de fundamental importância para o desempenho das equipes nos jogos, as respostas escolhidas para a resolução dos problemas inerentes ao jogo estão condicionadas ao entendimento e conhecimento que os jogadores apresentam (GARGANTA, 1998). Deste modo, os estudos no futebol centram-se cada vez mais na vertente tática e na tomada de decisão como seu principal enfoque (COSTA; NASCIMENTO, 2004; GARGANTA, 1997; GIACOMINI; GRECO, 2008; SISTO; GRECO, 1995).

Em função da evolução das metodologias de ensino dos jogos esportivos coletivos, os jogos reduzidos passaram a ocupar papel de destaque no treinamento de equipes já que estes permitem o desenvolvimento global das qualidades inerentes a cada modalidade (VELEIRINHO, 1999). Sendo assim, é possível atingir adaptações específicas que emergem do contexto do jogo (CASTELO, 2000). A partir deles, é possível desenvolver as vertentes táticas (COSTA et al., 2009b; GARGANTA, 1997; FIGUEIRA; GRECO, 2008;), técnicas (GRANT et al., I 999; MATTA; GRECO, 1996; PLATT et al., 200 I) e físicas (RAMPININI et al., 2007; REILLY, 2005). Para isso os treinadores optam pela utilização de variadas formatações, alterando-se o tamanho do campo, tempo e número de jogadores, permitindo a incorporação deste método aos mais diversos objetivos de treino (GRAÇA, 1994; VELEIRINHO, 1999).

Normalmente as atividades propostas nos treinamentos e as instruções repassadas nos jogos são baseadas em uma metodologia estruturada que se funde às concepções de jogo e de treino do treinador. Deste modo, o modelo de ensino adotado pelos treinadores influencia o processo de ensino-aprendizagem das ações táticas. Em função disso, já se verificam vários estudos que focam as atenções nos modelos de treinamento, procurando encontrar a forma mais eficaz de ensinar as modalidades esportivas (CHANDLER; MITCHELL, 1990; HOLT; STREAN; BENGOECHEA, 2002; MITCHELL; OSLIN, 1999; RINK, 1996; THORPE; BUNKER; ALMOND, 1986; TURNER; MARTINEK, 1995).

Dentre as diversas abordagens de ensino e treino, o Teaching Games for Understanding (TGfU) tem ganhado mais notoriedade, devido à ênfase da valência tática e da sua interação complexa com a técnica, o conhecimento, a compreensão, a tomada de decisão e a capacidade de ação em situação de jogo (COSTA et al., 
20 l0). Nesta abordagem, os alunos são ensinados a apreciar a forma avançada de jogo através da participação num contexto modificado, que será apropriado para o seu estágio de desenvolvimento físico, social e cognitivo. Esta apreciação convida os alunos a tornarem-se taticamente conscientes de como jogar, de forma a ganhar vantagem sobre os seus oponentes (THORPE; BUNKER; ALMOND, 1986). Com a tomada de consciência tática, o aluno é capaz de tomar decisões apropriadas acerca do que fazer e como o fazer. Quando os alunos tomam decisões de executar determinada habilidade técnica, fazem-na porque estão taticamente conscientes da necessidade dessa habilidade (HOPPER, 2002).

Os investigadores que apoiam este modelo de ensino sugerem que no processo de ensino-aprendizagem a exposição constante das crianças a situações de jogo ajuda na aquisição e desenvolvimento de conhecimento tático declarativo e processual e, consequentemente, na melhoria das decisões táticas tomadas (THORPE; BUNKER; ALMOND, 1986). Griffin, Mitchell e Oslin ( 1997) fornecem três argumentos de peso que justificam o emprego deste modelo de ensino. $O$ primeiro refere-se ao interesse e entusiasmo dos alunos no jogo e nas formas jogadas, utilizando-os como um fator positivo de motivação e como tarefas predominantes na estrutura do modelo. $O$ segundo argumento defende que o conhecimento é fator estruturante na forma de jogar, permitindo aos alunos serem melhores jogadores a partir da melhoria da sua compreensão do jogo, e, simultaneamente, menos dependentes do professor nas tomadas de decisões e na sua participação. Terceiro, os alunos podem transferir a sua compreensão e execução entre vários jogos desportivos com as mesmas características.

Partindo destes pressupostos, e com o intuito de contribuir no processo de ensino-aprendizagem no futebol, este estudo teve por objetivo avaliar quais os comportamentos táticos podem ser alterados após 20 sessões de treino.

\section{MATERIAL E MÉTODOS}

\section{AMOSTRA}

Foram avaliados 18 jogadores de futebol do sexo masculino da categoria sub- |4. Os jogadores executaram 2067 ações táticas, sendo 986 no teste, antes do período de treinos, e I08 I no reteste, após período de treinos.

\section{PROCEDIMENTOS ÉTICOS}

presente estudo foi aprovado pelo Comitê de Ética em Pesquisas com Seres Humanos da Universidade Federal de Viçosa (CEPH) (Of. Ref. No 132/20 I 2/ Comitê de Ética) e respeita as normas instituídas pelo Conselho Nacional em Saúde ( 1996) e pelo Tratado de Ética de Helsinki ( 1996) para pesquisas realizadas com seres 
humanos. A recolha de dados foi efetuada com o consentimento dos responsáveis legais do clube, dos pais e dos jogadores, a partir do preenchimento do termo de consentimento livre e esclarecido antes da realização dos testes e treinos.

\section{PROCEDIMENTOS DE RECOLHA DE DADOS}

A recolha de dados foi realizada em três etapas: Na primeira etapa foi feita uma avaliação diagnóstica dos comportamentos táticos dos jogadores, utilizando-se o FUT-SAT (COSTA et al., 20 I I).

A segunda etapa refere-se ao processo de treino no qual os jogadores foram submetidos. Este período de treino foi composto por 20 sessões com duração total de 1255 minutos, baseada na abordagem Teaching Games for Understanding (TGfU) (THORPE; BUNKER; ALMOND, 1986). As sessões de treino foram planejadas pelo treinador e tinham como objetivo principal qualificar as capacidades defensivas da equipe a partir de atividades que priorizassem uma melhoria no posicionamento dos jogadores entre as linhas longitudinais e transversais da equipe. Deste modo, para as ações defensivas, optou-se por desenvolver um maior número de atividades voltadas aos princípios "Cobertura Defensiva", "Equilíbrio" e "Concentração". Todavia, para treinar estes princípios defensivos primou-se também por realizar um maior número de atividades com ênfase nas ações ofensivas vinculadas aos princípios "Cobertura Ofensiva" e "Espaço", uma vez que as ações vinculadas a estes princípios requerem dos jogadores a realização de comportamentos relacionados aos três princípios da fase defensiva treinados (COSTA et al., 2009c). O tempo gasto nas atividades relacionadas aos princípios estão demonstradas no Quadro I a seguir.

Quadro I. Informações sobre o tempo total de treinamento dos princípios táticos nas 20 sessões de treino

\begin{tabular}{|l|l|c|}
\hline Princípio Tático & Sessões de treino utilizadas & Tempo (minutos) \\
\hline Ofensivos & 18 & 13 \\
Penetração & $1,3,5,7,8,11,14,16$ e 17 & 231 \\
Cobertura Ofensiva & $1,2,3,5,6,7,8,11,12,13,14,15$ e 20 & 322 \\
Espaço & $2,6,12$ e 18 & 42 \\
Mobilidade & $10,13,17,18$ e 19 & 67 \\
Unidade Ofensiva & & \\
Defensivos & $3,4,9$ e 20 & 97 \\
Contenção & $5,8,10,12,13,18$ e 19 & 140 \\
Cobertura Defensiva & $2,3,4,6,9,12$ e 15 & 185 \\
Equilíbrio & $2,3,10,13,16$ e 19 & 101 \\
Concentração & 16 e 17 & 57 \\
Unidade Defensiva & & 1255 \\
TOTAL & & \\
\hline
\end{tabular}


Na terceira etapa efetuou-se a reaplicação do FUT-SAT, seguindo exatamente o mesmo protocolo da primeira etapa.

\section{INSTRUMENTO DE RECOLHA E ANÁLISE DOS DADOS}

O instrumento utilizado para a recolha de dados foi o FUT-SAT, validado por Costa e colaboradores (20 I I). $O$ teste de campo deste sistema é aplicado em um espaço reduzido de 36 metros de comprimento por 27 metros de largura, com uma configuração de GR3 vs. 3GR (goleiro + 3 jogadores vs. 3 jogadores + goleiro), durante 4 minutos de jogo.

O FUT-SAT leva em conta dez princípios táticos fundamentais do futebol, sendo cinco para a fase ofensiva: i) penetração, ii) cobertura ofensiva, iii) mobilidade, iv) espaço e v) unidade ofensiva; e cinco para a fase defensiva: i) contenção, ii) cobertura defensiva, iii) equilíbrio, iv) concentração e v) unidade defensiva (COSTA, 20 I0). As variáveis relacionadas a estes princípios se organizam em duas macrocategorias e sete categorias. Na Macrocategoria Observação avalia-se as variáveis das categorias Princípios Táticos, Localização da Ação no Campo de Jogo e Resultado da Ação; e na Macrocategoria Produto avalia-se as variáveis das categorias Índice de Performance Tática - IPT, Percentual de Erros e Localização da Ação Relativa aos Princípios - LARP.

Para gravação dos comportamentos desempenhados no teste de campo utilizou-se uma câmara digital PANASONIC modelo NV - DS35EG. O material de vídeo foi repassado em um computador portátil (marca Toshiba Satellite modelo A300-I Co processador Intel T9300) via cabo (IEEE 1394) para conversão em arquivo ".avi". Para tratamento das imagens e análise dos jogos foram utilizados os softwares Utilius VS e Soccer Analyser (COSTA et al., 2009a).

\section{PROCEDIMENTO DE ANÁLISE DOS DADOS}

A análise descritiva das categorias Princípios Táticos, Localização da Ação no Campo de Jogo e Resultado da Ação baseou-se em análises de frequência, percentual e variação percentual. Já para as variáveis das categorias IPT, Percentual de Erros, Ações Táticas e LARP realizou-se análises de média e desvio padrão.

Para comparar as frequências das variáveis das categorias Princípios Táticos, Localização da Ação no Campo e Resultado da Ação utilizou-se o teste Qui-quadrado $\left(c^{2}\right)$, com $p \leq 0,05$. Para as categorias IPT, Percentual de Erros, Ações Táticas e LARP 
foi realizado o teste de normalidade de Shapiro Wilk para verificar a distribuição dos dados das variáveis. Nas variáveis com distribuição normal a comparação entre o teste e reteste foi efetuada a partir do teste $T$ de medidas independentes $(p \leq 0,05)$ e para os dados não paramétricos utilizou-se o teste de Mann-Whitney $\cup(p \leq 0,05)$.

Para a realização destas análises recorreu-se ao software SPSS (Statistical Package for Social Science) for Windows ${ }^{\circledR}$, versão 17.0.

\section{ANÁLISE DA FIABILIDADE}

A fiabilidade foi aferida com a reavaliação de 306 ações táticas ( | 4,8 | \%), que atende o valor de 10\% recomendado por Tabachnick e Fidell (2007). As avaliações foram realizadas por três observadores treinados e respeitando um intervalo de 2 I dias (ROBINSON; O'DONOGHUE, 2007). Recorreu-se ao teste de Kappa de Cohen para os cálculos e verificou-se que as fiabilidades intra e inter avaliadores situaram-se entre 0,90 e 0,94 com erro padrão inferior a 0,02; sendo classificada pela literatura como "perfeita" (LANDIS; KOCH, 1977).

\section{RESULTADOS}

Os resultados serão expostos em função das macrocategorias de variáveis dependentes do estudo. Assim, serão primeiramente relatados os resultados das categorias Princípios Táticos, Localização da Ação no Campo de Jogo e Resultado da Ação e, posteriormente, os resultados das categorias Índice de Performance Tática - IPT, Percentual de Erros e Localização da Ação Relativa aos Princípios - LARP.

\section{MACROCATEGORIA OBSERVAÇÃO}

A Tabela I apresenta as frequências, os percentuais e a variação percentual das variáveis das categorias Princípios Táticos, Localização da Ação no Campo de Jogo e Resultado da Ação no teste e reteste. Das 25 variáveis apresentadas na Tabela, três apresentaram diferenças significativas entre o teste e reteste.

A partir da Tabela I verifica-se que no "Total" de ações táticas realizadas pelos jogadores há diferenças significativas entre o teste e o reteste, demonstrando que no reteste os jogadores efetuaram maior número de ações. 
Tabela I. Frequência, percentual e variação das variáveis das categorias Princípios Táticos, Localização da Ação no Campo de Jogo e Resultado da Ação no teste e reteste

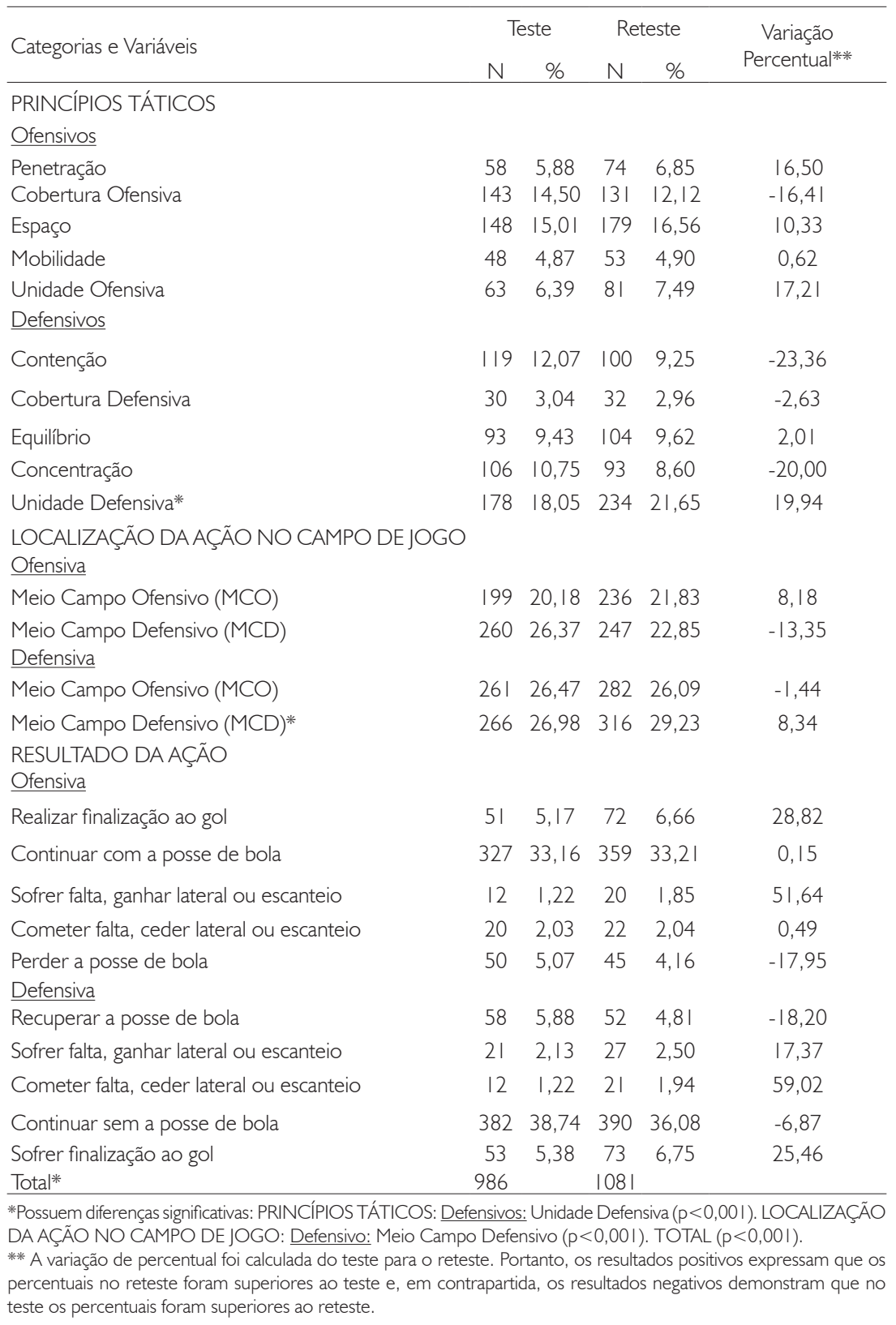


Nas variáveis da categoria Princípios Táticos verificaram-se diferenças significativas entre o teste e o reteste em um dos dez princípios que compõem a grelha de avaliação, nomeadamente a "Unidade Defensiva". Já em função da variação percentual entre as duas avaliações observa-se maior disparidade nas ações ofensivas na variável "Unidade Ofensiva" e nas ações defensivas associadas à variável "Contenção". Verificaram-se também as menores variações percentuais nas ações ofensivas e defensivas para as variáveis "Mobilidade" e "Equilíbrio", respectivamente.

Para as variáveis da categoria Localização da Ação no Campo de Jogo foram encontradas diferenças significativas nas ações defensivas efetuadas no "Meio Campo Defensivo". A partir dos resultados de variação percentual, verifica-se que a maior disparidade entre o teste e reteste encontra-se nas ações ofensivas executadas em "Meio Campo Defensivo". Já a menor variação entre as avaliações decorre nas ações defensivas em "Meio Campo Ofensivo".

Na categoria Resultado da Ação não foram encontradas diferenças significativas. Em função das variações percentuais verifica-se maior distinção entre as duas avaliações nas ações defensivas associadas à variável "Cometer falta, ceder lateral ou escanteio". A menor variação de percentual situa-se nas ações ofensivas na variável "Cometer falta, ceder lateral ou escanteio".

\section{MACROCATEGORIA OBSERVAÇÃO}

A Tabela 2 apresenta a média e o desvio padrão das variáveis das categorias IPT, Percentual de Erros e LARP no teste e reteste. Das trinta e nove variáveis expostas na tabela, duas apresentaram diferenças significativas. 
Tabela 2. Médias e desvios padrões das variáveis das categorias Índice de Performance Tática (IPT), Percentual de Erros e Localização da Ação Relativa aos Princípios (LARP) no teste e reteste

\begin{tabular}{cccccc}
\hline Índice de Performance Tática & Percentual de Erros & \multicolumn{2}{c}{$\begin{array}{c}\text { Localização da Ação } \\
\text { Relativa aos Princípios }\end{array}$} \\
Teste & Reteste & Teste & Reteste & Teste & Reteste \\
\hline
\end{tabular}

Ofensivos

Penetração $\quad 50,9| \pm| 7,13 \quad 59,22 \pm 20,9|\quad 25,85 \pm 37,5| \quad|7,16 \pm| 6,53 \quad|, 44 \pm 1,20 \quad|, 47 \pm 1,42$

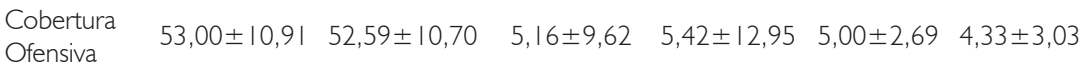

Mobilidade

$64,29 \pm 18,20 \quad 63,67 \pm 14,68 \quad 4,64 \pm 12,16 \quad 3,56 \pm 7,40 \quad 0,43 \pm 0,65 \quad 0,47 \pm 1,06$

Espaço

$42,92 \pm 5,86 \quad 44,11 \pm 8,05$

$3,50 \pm 10,60 * 7,34 \pm 9,39 * 6,11 \pm 3,07 \quad 7,76 \pm 2,02$

Unidade

Ofensiva

$55,08 \pm 20,52 \quad 59,08 \pm 17,07 \quad 20,67 \pm 29,22 \quad 6,94 \pm 11,87 \quad 2,00 \pm 1,84 \quad 2,22 \pm 1,56$

Defensivos

Contenção $\quad 26,03 \pm 10,62 \quad 29,25 \pm 20,58 \quad 58,44 \pm 24,92 \quad 55,19 \pm 29,014,00 \pm 2,61 \quad 2,83 \pm 1,50$

Cobertura

Defensiva

$35,36 \pm 22,19 \quad 39,44 \pm 22,35 \quad 32,14 \pm 38,38 \quad 26,11 \pm 30,350,43 \pm 0,51 \quad 0,67 \pm 0,90$

Equilíbrio $\quad 30,55 \pm 15,67 \quad 30,70 \pm|4,8| \quad 50,50 \pm 28,20 \quad 56,17 \pm 19,031,94 \pm 1,76 \quad 1,89 \pm 1,57$

Concentração $30,65 \pm 10,41 \quad 31,53 \pm 13,06 \quad 25,90 \pm 30,04 \quad 14,59 \pm 15,433,22 \pm 1,35 \quad 2,56 \pm 1,15$

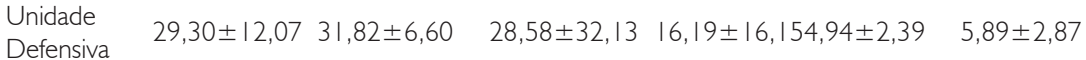

Fase do jogo

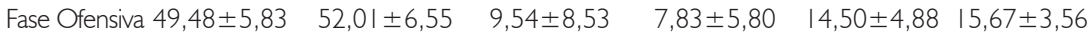

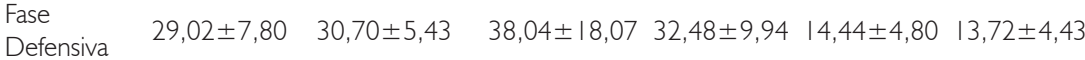

Jogo $\quad 38,55 \pm 3,50 * 41,31 \pm 4,03 * 24,54 \pm 8,74 \quad 20,40 \pm 5,68 \quad 28,94 \pm 5,64 \quad 29,39 \pm 4,79$

Possuem diferenças significativas $(p<0,05)$. IPT: Total $(p=0,03)$. Percentual de Erros: Espaço $(p=0,02)$.

Verificaram-se diferenças significativas na categoria IPT entre os momentos na variável "Jogo", sendo que no reteste a média foi maior que no teste.

Na categoria Percentual de Erros a variável "Espaço" apresentou diferenças significativas entre as etapas de aplicação do teste. No teste os jogadores erraram menos que no reteste.

$\mathrm{Na}$ categoria LARP não foram encontradas diferenças significativas entre o teste e o reteste. 


\section{DISCUSSÃO}

Este trabalho teve por objetivo avaliar quais os comportamentos táticos podem ser alterados após 20 sessões de treino. Através dos resultados pode-se constatar que o desempenho tático dos jogadores foi alterado em quatro das 64 variáveis avaliadas neste estudo.

A partir das diferenças significativas encontradas nas variáveis da categoria Princípios Táticos da fase defensiva, verifica-se que os jogadores efetuaram mais ações de "Unidade Defensiva" no reteste em relação ao teste. O princípio da "Unidade Defensiva" possui uma forte relação com a compreensão de jogo por parte dos jogadores e do modelo de jogo preconizado pela equipe. Deste modo, os resultados encontrados na variável Localização da Ação no Campo de Jogo na fase defensiva podem traduzir o aumento da realização do princípio "Unidade Defensiva", uma vez que os jogadores marcaram mais recuados e, consequentemente, promoveram um maior número de ações características desse princípio. A concepção unitária de defesa de uma equipe passa pela consciência de todos os jogadores sobre a importância das suas movimentações, dos seus limites e das suas posições em relação aos companheiros, a bola e os adversários (HAINAUT; BENOIT, I979; TESSIE, 1969). Nas sessões de treino onde foi abordado o princípio de "Unidade Defensiva", o objetivo das atividades era de garantir a coesão, efetividade e equilíbrio funcional entre as linhas longitudinais e transversais da equipe. De acordo com Garganta e Pinto ( 1994) para conseguir isto, os jogadores responsáveis por cumprir o princípio da "Unidade Defensiva", necessitam organizar os seus deslocamentos, em função da variabilidade das situações momentâneas de jogo e do conhecimento das capacidades e possibilidades de movimentação dos seus companheiros.

Verificou-se que no reteste os jogadores marcaram mais recuados em relação ao teste, uma vez que, a partir dos resultados da categoria Localização da Ação no Campo de Jogo foram encontradas diferenças significativas nas ações defensivas executadas no meio campo defensivo. Apesar disso, o padrão de marcação manteve-se semelhante, pois tanto no teste como no reteste foram efetuadas mais ações ofensivas e defensivas no meio campo defensivo, ou seja, optou-se por marcar mais vezes em bloco baixo e efetuar mais ações ofensivas no setor defensivo para supostamente aumentar o espaço de jogo efetivo, e assim favorecer a exploração de espaços livres e oferecer melhores condições ao portador da bola.

Estes achados revelam-se importantes para esta categoria, porque as ações táticas destes princípios estão relacionados com a utilização eficiente do espaço de jogo e à noção espacial do jogo que, de acordo com a literatura, ainda encontra-se em formação entre jogadores da categoria Sub- 4 (GARGANTA; PINTO, 1994; GRECO, 1998). 
Na categoria Percentual de Erros foram encontradas diferenças significativas na variável "Espaço". Os resultados indicam que os jogadores de ataque tiveram mais dificuldades em realizar as ações relativas a este princípio no reteste. Isto demonstra que a equipe adversária, ou seja, a equipe defensora, criou mais dificuldades para a ocupação e exploração de espaços importantes para a continuidade da ação ofensiva (SOLOMENKO, 1982).

Na categoria Índice de Performance Tática que transcreve o desempenho dos jogadores, observa-se que não foram encontradas diferenças significativas nos princípios avaliados. Além disso, as sessões de treino não proporcionaram melhoria significativa na performance dos princípios defensivos priorizados pelo treinador ("Cobertura Defensiva", "Equilíbrio" e "Concentração"). Duas possíveis explicações para este resultado residem no fato do tempo destinado nas atividades não ter sido suficiente para qualificar as ações táticas destes princípios, e no fato de que os jogadores da equipe adversária melhoram o seu desempenho ofensivo, o que provoca, como consequência, mais dificuldades para a organização defensiva.

Estas hipóteses são subsidiadas pelos resultados encontrados no Índice de Performance Tática de "Jogo", onde pode ser verificada uma melhoria na performance tática dos avaliados, quando todos os princípios táticos são avaliados em conjunto. Assim, apesar do treino proposto não ter proporcionado melhorias específicas nos princípios táticos fundamentais do jogo, observou-se que os jogadores obtiveram uma progressão na execução dos comportamentos táticos e, consequentemente, na compreensão do jogo coletivo.

Verificaram-se também diferenças significativas entres as duas avaliações no total de ações táticas realizadas, onde no reteste os jogadores executaram mais ações que no teste. O fato de o TGU ser um modelo centrado no jogo e no aluno, propõe como ação inicial a escolha de uma forma de jogo que permite aos jogadores com dificuldades de realizar ações técnicas, a possibilidade de encarar as situações de jogo de uma maneira inteligente, impulsionando a capacidade de interpretar situações, perceber possibilidades de ações e de agir com intencionalidade de acordo com os objetivos do jogo (GRAÇA, 2007). Uma vez que o TGfU permite potencializar as capacidades de percepção e tomada de decisão dos jogadores, o número de ações táticas preconizadas pelo teste tendem a aumentar (HOPPER, 2002). Neste caso, as sessões de treino demonstraram tais resultados e, além disso, estimularam o aumento de ações que resultam em finalização ao gol.

De acordo com Metzler (2000), a potencial riqueza do processo de ensino aprendizagem resulta do cuidado na adequação das atividades e métodos de instrução promovidos às características e vulnerabilidades dos alunos, em consonância com os objetivos a alcançar. Deste modo, os resultados verificados e discutidos 
anteriormente destacam que o treinamento fundamentado a partir do modelo TGfU pode garantir melhorias nos comportamentos táticos dos jogadores de futebol. Este modelo coloca o aluno perante situações-problema que impulsionam a necessidade de encontrar a solução mais eficaz, onde a tomada de decisão assume uma crucial importância e onde o desenvolvimento das habilidades do jogo ocorre dentro do seu contexto ecológico como meio para a progressão da capacidade de jogo (GRAÇA, 2003). Nesse sentido, a vivência esportiva deve ser abordada como um momento em que o aluno está inserido em um contexto complexo, em uma rede de elementos que possibilitam uma multiplicidade de ação e reflexão.

\section{CONCLUSÕES}

Através dos resultados pode-se constatar que o desempenho tático dos jogadores avaliados apresentou alteração em quatro das 64 variáveis táticas avaliadas pelo FUT-SAT. Os resultados revelaram que os jogadores efetuaram maior número de ações táticas no reteste e também desempenharam mais ações do princípio "unidade defensiva".

Também verificou-se que no reteste os jogadores efetuaram mais ações defensivas no meio campo defensivo, demonstrando que os jogadores marcaram mais recuados na avaliação posterior às sessões de treinamento. Apesar disso, o padrão de marcação manteve-se semelhante nos dois testes, onde optou-se por marcar mais vezes em bloco baixo e efetuar mais ações ofensivas no setor defensivo.

Já em relação ao Índice de Performance Tática verificou-se que as sessões de treino baseadas no TGfU proporcionaram melhorias no desempenho tático global dos jogadores avaliados, mostrando que elas foram importantes para a melhoria da compreensão de jogo coletivo.

\section{Which Tactical Behaviors from Under- 14 Youth Soccer Players Might be Improved After 20 Training Sessions?}

ABSTRACT: The aim of this paper was to assess which tactical behaviors might be modified after 20 training sessions. The sample comprised $18 \mathrm{U}$ - 14 youth soccer players. The instrument used to assess the tactical behaviors was FUT-SAT and the training sessions were based on the Teaching Games for Understanding. Significant differences were verified in four variables: the Tactical Principle "defensive unity", the total amount of tactical actions performed, the Tactical Performance Index and the Percentage of Errors in the Tactical Principle "width and length". It was concluded that the training sessions were effective, especially regarding the increase of the Game's Tactical Performance Index.

KEYWORDS: Soccer; Tactics; Training; Teaching Games for Understanding. 
¿Qué comportamientos tácticos de jugadores de fútbol del u- 14 se pueden modificar después de 20 sesiones de entrenamiento?

RESUMEN: El objetivo de este trabajo fue evaluar qué comportamientos tácticos se pueden modificar después de 20 sesiones de entrenamiento. La muestra constó de 20 jugadores del U- 14. El instrumento usado para evaluación de los comportamientos tácticos fue el FUT-SAT y las sesiones de entrenamiento fueron basadas en el Teaching Games for Understanding. Fueron verificadas diferencias significativas en cuatro variables: el Principio Táctico "unidad defensiva", el total de acciones tácticas realizadas, el Indicador de Desempeño Táctico de Juego y el Porcentual de Errores en el Principio Táctico "espacio". Se concluyó que los entrenamientos fueron eficaces, especialmente en lo que respecta el aumento del Indicador de Desempeño Táctico del Juego.

PALABRAS CLAVES: Fútbol; táctica; entrenamiento; Teaching Games for Understanding.

\section{REFERÊNCIAS}

CASTELO, J. Futebol: modelo técnico-tático do jogo. Lisboa: Gráfica 2000, 1994.

. Metodologia do treino desportivo. Lisboa: Faculdade de Motricidade Humana 2000.

CHANDLER, T. J. L.; MITCHELL, S. A. Reflections on 'models of games education'. Journal of Physical Education, Recreation and Dance, Reston, v. 6I, n. 8, p. 19-21, 1990.

COSTA, I. Comportamento tático no futebol: contributo para a avaliação do desempenho de jogadores em situações de jogo reduzido. 20 1 0. 266 f. Dissertação (Doutorado em Ciências do Desporto) - Faculdade de Desporto, Universidade do Porto, Porto, 2010.

COSTA, I. et al. Avaliação do desempenho tático no futebol: concepção e desenvolvimento da grelha de observação do teste "GR3-3GR". Revista Mineira de Educação Física, Viçosa, v. 17, n. 2, p. 36-64, 2009a.

- Influência de tipo de piso, dimensão das balizas e tempo de jogo na aplicação do Teste de GR3-3GR em Futebol. Lecturas: Educación Física y Deportes, Buenos Aires, año I4, n. 136, 2009b. Disponível em: <http://www.efdeportes.com/efd I 36/aplicacao-do-teste-de-gr3-3gr-em-futebol.htm>. Acesso em: 29 jan. 2012.

. Princípios táticos do jogo de futebol. Motriz, Rio Claro, v. I5, n. 3, p. I- I5, jul./ set. 2009c.

COSTA, I. T. et al. O teaching games for understanding (Tfu) como modelo de ensino dos jogos desportivos coletivos. Revista Palestra, Bucaramanga, v.7, p. 69-77, dec. 2010.

COSTA, I. et al. Sistema de avaliação táctica no futebol (fut-sat): desenvolvimento e validação preliminar. Revista Motricidade, Vila Real, v.7, n. I, p. 69-84. 201 I.

COSTA, L. C. A.; NASCIMENTO, J. V. O ensino da tática: novas abordagens metodológicas. Revista da Educação Física/UEM, Maringá, v. I 5, n. 2, p. 49-56, 2004. 
FIGUEIRA, F. M.; GRECO, J. P. Futebol: um estudo sobre a capacidade tática no processo de ensino-aprendizagem-treinamento. Revista Brasileira de Futebol, Viçosa, v. I, n. 2, p. 53-65, jul./dez. 2008.

GARGANTA, J. Modelação táctica do jogo de futebol: estudo da organização da fase ofensiva em equipas de alto rendimento. 1997. 318 f. Dissertação (Doutorado em Ciências do Desporto) - Faculdade de Ciências do Desporto e de Educação Física, Universidade do Porto, Porto, 1997.

. Analisar o jogo nos jogos desportivos colectivos: uma preocupação comum ao treinador e ao investigador. Horizonte, Lisboa, v. I4, n. 83, p. 7-14, maio/jun. 1998.

GARGANTA, J.; PINTO, J. O ensino do futebol. In: GRAÇA, A.; OLIVEIRA, J. (Org.) O ensino dos jogos desportivos. Porto: Rainho \& Neves, 1994. p. 95- 136.

GIACOMINI, D. S.; GRECO, P. J. Comparação do conhecimento tático processual em jogadores de futebol de diferentes categorias e posições. Revista Portuguesa de Ciências do Desporto, Porto, v. 8, n. I, p. 126-136, abr. 2008.

GRAÇA, A. Os comos e os quandos no ensino dos jogos. In: GRAÇA, A.; OLIVEIRA, J. (Org.) O ensino dos jogos desportivos. Porto: Rainho \& Neves, 1994. p. 27-34.

. O modelo de competência nos jogos de invasão. In: SEMINÁRIO DE EDUCAÇÃO FÍSICA: EDUCAÇÃO FÍSICA E O ENSINO FUNDAMENTAL, 7. 2003, São Paulo. Anais... São Paulo: Escola de Educação Física e Esporte da Universidade de São Paulo, 2003. p. 17-24.

- Modelos e concepções de ensino do jogo. Revista Portuguesa de Ciências do Desporto, Porto, v. 7, n. I, p. 9- 10, 2007.

GRANT, A. et al. Physiological and technical analysis of || $\mathrm{v}||$ and $8 \mathrm{v} 8$ youth football matches. Insight: the F. A. Coaches Association, Warwick, v. 3, n. 2, p. 29-31, 1999.

GRECO, P. J. Iniciação esportiva universal: metodologia da iniciação esportiva na escola e no clube. Belo Horizonte: Ed. da UFMG, 1998.

GRIFFIN, L.; MITCHELL, S.; OSLIN, J. Teaching sport concepts and skills: a tactical game approach. Champaign: Human Kinetics, 1997.

HAINAUT, K.; BENOIT, J. Enseignement des pratiques physiques specífiques: le football moderne- tactíque- techinique- lois du jeu. Bruxelas: Presses Universitaires de Bruxelles, 1979.

HOLT, N. L.; STREAN, W. B.; BENGOECHEA, E. G. Expanding the teaching games for understanding model: new avenues for future research and practice. Journal of Teaching in Physical Education, Champaign, v. 2 1, n. 2, p. 162-176, jan. 2002.

HOPPER, T. Teaching games for understanding: the importance of student emphasis over content emphasis. Journal of Physical Education, Recreation \& Dance, Reston, v. 73, n. 7, p. 44-48, sept. 2002. 
LANDIS, J. R.; KOCH, G. C. The measurement of observer agreement for categorical data. Biometrics, Arlington, v. 33, n. I, p. 159-174, mar. 1977.

MATTA, M. O.; GRECO, P. J. O Processo de ensino-aprendizagem-treinamento da técnica esportiva aplicada ao futebol. Revista Mineira de Educação Física, Viçosa, v. 4, n. 2, p. 34-50, 1996.

METZLER, M. W. Instructional models for physical education. Boston: Allyn and Bacon, 2000.

MITCHELL, S. A.; OSLIN, J. L. An investigation of tactical transfer in net games. European Journal of Physical Education, Worcester, v. 4, n. 2, p. 162-172, jan. 1999.

PLATT, D. et al. Physiological and technical analysis of $3 v 3$ and $5 v 5$ youth football matches. Insight: the facoaches association journal, Warwick, v. 4, n. 4, p. 42-45, 200 I.

RAMPININI, E. et al. Factors influencing physiological responses to small-sided soccer games. Journal of Sports Sciences, London, v. 25, n. 6, p. 659-666, apr. 2007.

REILLY, T. An ergonomics model of the soccer training process. Journal of Sports Sciences, London, v. 23, n. 6, p. 56I-572, jun. 2005.

REVERDITO, R. S.; SCAGLIA, A. J. A Gestão do processo organizacional do jogo: uma proposta metodológica para o ensino dos jogos coletivos. Motriz, Rio Claro, v. I3, n. I, p. 5 I-63, jan./mar. 2007.

RINK, J. E. Tactical and skill approaches to teaching sport and games. Journal of Teaching in Physical Education, Champaign, v. I5, n. 4, p. 397-4I6, july 1996.

ROBINSON, G.; O'DONOGHUE, P. G. A weighted kappa statistic for reliability testing in performance analysis of sport. International Journal of Performance Analysis in Sport, Cardiff, v. 7, n. I, p. 12-19, jan. 2007.

SISTO, F. F.; GRECO, P. J. C. Comportamento tático nos jogos esportivos coletivos. Revista Paulista de Educação Física, São Paulo, v. 9, n. I, p. 63-68, jan./jun. 1995.

SOLOMENKO, V. Juego sin balon. El Entrenador Español, Madrid, n. I 4, p. 72-75, out. 1982.

TABACHNICK, B.; FIDELL, L. Using multivariate statistics. $5^{\text {th }}$ ed. New York: Harper \& Row, 2007.

TEODORESCU, L. Problemas da teoria e metodologia nos jogos desportivos. Lisboa: Livros Horizontes, 1984.

TESSIE, J. Le football. Paris: Vigot Fréres, 1969.

THORPE, R.; BUNKER, D.; ALMOND, L. Rethinking games teaching. Loughborough: University of Technology, 1986.

TURNER, A. P.; MARTINEK, T. J. Teaching for understanding: a model for improving decision making during game play. Quest, Greensboro, v. 47, n. I, p. 44-63, feb. 1995. 
VELEIRINHO, A. O jogo reduzido. Pertinência e possibilidades no ensino dos jogos desportivos colectivos. In: TAVARES, F. (Org.). Estudos dos jogos desportivos: concepções, metodologias e instrumento. Porto: Faculdade de Ciências do Desporto e de Educação Física da Universidade do Porto, 1999. p. 69-76.

Recebido em: 4 mai. 2012 Aprovado em: II jun. 2013 Endereço para Correspondência: Prof. Israel Teoldo Costa Universidade Federal de Viçosa Departamento de Educação Física Núcleo de Pesquisas e Estudos em Futebol Av. PH Rolfs, s/n - Campus Universitário Viçosa-MG. CEP: 36570-000 E-mail: israel.teoldo@ufv.br Fone/Fax: 0XX (31) 3899-2249 